NBER WORKING PAPER SERIES

ACCELERATING ENERGY INNOVATION:

INSIGHTS FROM MULTIPLE SECTORS

Rebecca Henderson

Richard G. Newell

Working Paper 16529

http://www.nber.org/papers/w16529

\author{
NATIONAL BUREAU OF ECONOMIC RESEARCH \\ 1050 Massachusetts Avenue \\ Cambridge, MA 02138 \\ November 2010
}

We gratefully acknowledge funding from the Doris Duke Foundation and from an anonymous donor. The views expressed herein are those of the authors and do not necessarily reflect the views of the National Bureau of Economic Research.

NBER working papers are circulated for discussion and comment purposes. They have not been peerreviewed or been subject to the review by the NBER Board of Directors that accompanies official NBER publications.

(C) 2010 by Rebecca Henderson and Richard G. Newell. All rights reserved. Short sections of text, not to exceed two paragraphs, may be quoted without explicit permission provided that full credit, including $\odot$ notice, is given to the source. 
Accelerating Energy Innovation: Insights from Multiple Sectors

Rebecca Henderson and Richard G. Newell

NBER Working Paper No. 16529

November 2010

JEL No. O3

\begin{abstract}
$\underline{\text { ABSTRACT }}$
Re-orienting current energy systems toward a far greater reliance on technologies with low or no carbon dioxide emissions is an immense challenge. At the broadest level the histories presented here are very much consistent with widely held views within the energy innovation policy literature. In general, this literature has suggested that greatly increasing rates of energy innovation requires creating significant demand for low carbon technologies, substantially increased federal funding for "well-managed" research, and in at least some cases support for the initial deployment of new technologies. As the other markets explored in this volume do not face the same degree of unpriced environmental externality, there is no straightforward equivalent to a carbon price in the history of agriculture, chemicals, IT or biopharmaceuticals. Nonetheless, our authors outline a number of ways in which public policy has often stimulated demand, particularly in the early stages of a technology's evolution, and confirm that the expectation of rapidly growing demand appears to have been a major stimulus to private sector investment in innovation. Each history also confirms the centrality of publicly funded research to the generation of innovation, particularly in the early stages of an industry's history, and highlights a range of institutional mechanisms that have enabled it to be simultaneously path breaking and directly connected to industrial practice.

Our histories depart somewhat from the bulk of the energy innovation policy literature in focusing attention on the role of vigorous competition - particularly entry - in stimulating innovation, suggesting that in several industries a mix of public policies - including procurement, antitrust and intellectual property protection - played an important role in stimulating innovation by encouraging extensive competition and entry by newly founded firms. Many of the most innovative industries profiled here have been characterized by a lively "innovation ecosystem" that both rapidly incorporated the results of publicly funded research and supports widespread private sector experimentation and rapid entry. There are, of course important differences between the industries profiled here and the energy sector, but we believe that exploring the potential of these kinds of innovation ecosystems in clean energy might be a fruitful avenue for future research.
\end{abstract}

Rebecca Henderson

Heinz Professor of Environmental Management

Harvard Business School

Morgan 445

Soldiers Field

Boston, MA 02163

and NBER

rhenderson@hbs.edu

Richard G. Newell

Nicholas School of the Environment

Duke University

Box 90227

Durham, NC 27708

richard.newell@duke.edu 


\title{
Accelerating Energy Innovation: Insights from Multiple Sectors
}

\author{
Chapter One: Introduction and Summary \\ Rebecca Henderson and Richard G. Newell ${ }^{1}$
}

This version: August 23, 2010

Re-orienting current energy systems toward a far greater reliance on technologies with low or no carbon dioxide emissions is an immense challenge. Fossil fuels such as oil, coal, and natural gas together satisfy 81 percent of global energy demand and generate 69 percent of global anthropogenic greenhouse gas emissions (IEA 2009). Moreover worldwide demand for energy is expected to increase by about 40 percent over the next twenty years, with most of this increase occurring in non-OECD countries (IEA 2009, EIA 2010).

Meeting this demand without significantly increasing global emissions using currently available technology would be costly. For example, the International Energy Agency projects that about \$26 trillion of investment in energy-supply infrastructure will be needed over the 2008-2030 period simply to meet projected increases in energy demand (IEA 2009). ${ }^{2}$ Modeling scenarios of cost-effective global climate mitigation policy suggest that, for atmospheric stabilization targets in the range of 450-550 parts per million $\mathrm{CO}_{2}$, the cost of GHG mitigation through 2050 without significant innovation in the underlying technologies would require additional trillions or tens of trillions of dollars (Newell 2008). Longer-term total costs through 2100 could be approximately double this amount.

Plausible developments in energy efficiency, bioenergy, wind, solar, nuclear and low-emitting fossil fuel technologies could greatly reduce these costs. For example, Edmonds et al. (2007), suggest that significant innovation could reduce the present-value cost of achieving $\mathrm{CO}_{2}$ stabilization at $550 \mathrm{ppm}$ by more than $\$ 20$ trillion. Other studies have found that the cumulative costs of achieving any given stabilization target are reduced by 50 percent or more under advanced technology scenarios (see, e.g., Manne and Richels 1992 and Clarke et al. 2006). Accelerating innovation and technology adoption in energy is thus crucial to meeting greenhouse gas mitigation goals.

Given this urgency it is not surprisingly that a flood of recent books and articles have explored how the U.S. energy innovation system could be improved (See, for example, work by Anadon and Holdren 2009; Gallagher, Holdren and Sagar, 2006; Gallagher, Anadon and Bunn, 2009; Grübler et al., 1999; Lester, 2009; Narayanamurti et al. 2009a, 2009b; Newell 2008; Nemet and Kammen, 2007; Ogden, Podesta and Deutch, 2008; Scott 2009 and Weiss and Bonvillian 2009).

\footnotetext{
1 Rebecca Henderson is the Senator John Heinz Professor of Environmental Management at Harvard Business School and a research fellow at the National Bureau of Economic Research. Richard Newell completed his work on this paper as the Gendell Associate Professor of Energy and Environmental Economics at Duke University's Nicholas School of Environment, when he was also a Research Associate at the National Bureau of Economic Research and a University Fellow at Resources for the Future. He is currently on leave from Duke University as Administrator of the U.S. Energy Information Administration (EIA).

2 This figure does not include expenditures on energy demand-side technologies (e.g., transportation, appliances, and equipment), investment demand for which will measure in the trillions of dollars each year.
} 
By and large this is tightly argued and persuasive work that is a critically important starting point for anyone interested in effective energy policy. This book explores the same questions using a complementary approach. Instead of focusing on the history of the energy industry to draw lessons for the future of energy innovation, it explores the history of innovation in several industries that have already seen extraordinary rates of technological progress: in agriculture, chemicals, semiconductors, computers, the internet and biopharmaceuticals. Each of the chapters that follow explores the complex role that public policy and private markets have played in triggering rapid innovation in the industry and in sustaining it once in motion. Each industry differs from the energy sector in important ways, but we nonetheless believe that this approach provides a useful complement to the existing literature.

In the first place, the history of each industry reminds us that relatively rapid, transformational innovation can occur. Innovation in agriculture was a critical factor in reducing the manpower needed to grow the nation's crops from 49 percent of the U.S. workforce in 1880 to less than 2 percent in 2000. The chemical industry created entirely new materials and fuels, laying the foundation both for progress in existing industries - as in the case of synthetic pesticides and fertilizers - and for the creation of entirely new ones, including plastics and synthetic fibers. Innovation in the IT industry appears to have greatly increased the productivity of the U.S. economy: Jorgenson (2004) estimates that the quality-adjusted price of computers dropped at an annual average of 16 percent during 1959-2001, and that this rate of decline doubled after the mid-1990s, while Berndt and Rappaport (2001) report that personal computer prices declined an average of 35 percent a year between 1992 and 2002. The Internet has clearly changed all our lives and the net effect of IT and telecommunications investment on national productivity appears to be quite high (Brynjolfsson and Hitt, 2003; Jorgenson and Stiroh, 2000). In the case of life sciences, major breakthroughs in areas such as heart disease, cancer and HIV have significantly reduced mortality rates (Cockburn 2007, Lichtenberg 2005; Duggan and Evans 2008). In each of these cases - with the possible exception of chemicals - well funded, well managed federal research laid the foundation for an industry that created great prosperity and that continues to be dominated by American firms.

The second reason that we believe that exploring the history of innovation in other industries may be useful is that it provides an intriguing perspective on some of the policy recommendations currently being advanced for the energy industry. Taken together the histories point to three key factors as critical to accelerating innovation: (1) well funded, carefully managed public research that is tightly linked to the private sector; (2) rapidly growing demand; and (3) antitrust, intellectual property and standards policies that together promote vigorous competition and the entry of new firms. Expressed at this level of generality these results echo the fundamental findings of an innovation policy literature that stretches back to Vannevar Bush (1945). Many scholars have noted the critical role played by well managed federal research funds in shaping the United States' most innovative industries, and the idea that effective innovation feeds off both technology "supply" and market "demand" is a well established one (Mowery and Rosenberg, 1979). The innovation policy literature has focused less on the role of competition and new entrants in shaping innovation, but the intuition that new firms may have a critical role in spurring innovation goes back to Schumpeter (1934) and has recently been confirmed in a number of important studies (Aghion, Bloom and Blundell, 2005; Aghion et. al. 
2007). They are also broadly consistent with the bulk of the recommendations currently being made for accelerating innovation in energy.

But in innovation policy the devil is in the details - particularly in the details of organizational implementation - and conclusions at this level of generality abstract from the critical institutional detail that is characteristic of each industry and that is particularly well captured in the chapters. The energy policy literature stresses the importance of adequate federal funding and the development of tight linkages between the public and private sectors (Anadon and Holdren 2009; Gallagher, Holdren and Sagar, 2006; Gallagher, Anadon and Bunn, 2009; Lester, 2009). It explores the critically important role of designing policy instruments that will support demand for low carbon technologies (Newell 2008; Nemet and Kammen, 2007) and the potential role of intellectual property regimes in shaping innovation diffusion (Sagar and Anadon, 2009). But most importantly it stresses the critical need for the development of a comprehensive innovation strategy that can coordinate policy across multiple entities and for the design of institutional structures that ensure public money does not become pork (Lester, 2009, Ogden, Podesta and Deutch, 2008; NCEP 2009; Weiss and Bonvillian, 2009). In presenting the detailed histories of five industries where the delicate balance between public funding and private markets was maintained productively for many years we hope to contribute in an important way to the conversation about exactly how these kinds of strategic and organizational choices can best be made.

Similarly much of the current energy innovation policy literature stress the potential importance of public funding of "deployment" - or of supporting the initial implementation of new energy technologies given their probable risk and scale. In four of the industries discussed here - in agriculture, semiconductors, computers and the internet -- the federal government played an important role in funding deployment of the new technology. Again, in presenting detailed case examples of the variety of ways in which the federal government filled this role we hope to stimulate useful debate about what might be most appropriate in the case of energy.

A comparison between contemporary prescriptions for energy innovation and the history of accelerated innovation in a range of other industries is also intriguing because it highlights a number of cases in which the two are significantly different. The current energy policy literature, for example, focuses much more on innovation "supply" (public and private funding for research) and on innovation "demand" (the use of policy instruments to create demand for low carbon energy) than it does on the instruments of competition policy. One of the striking findings from our industry histories, for example, is the (often seemingly unintended) role of antitrust and procurement policy in enabling widespread entry into the innovating industry. The histories also stress the important role that federally funded research has played in generating highly trained human capital for the private sector, an issue that has been stressed in some of the current energy innovation policy literature (Newell 2008, 2010), but not broadly so.

The remainder of this introduction frames the volume by attempting to draw together some of the key themes that occur across the chapters. The book then opens with Richard Newell's brief overview of the history of innovation in energy. The energy sector is vast and highly complex, 
but nonetheless Newell sketches out some "central tendencies" that provide important background for the chapters that follow. In Chapter 3 Brian Wright and Tiffany Shih describe the history of innovation in agriculture, an industry that - in its time - had the scale and reach of the energy sector in our own day, and in which both local funding for diffusion and federally funded innovation proved to be critical. Their chapter also raises a number of important issues around the role of intellectual property rights and public/private partnership in framing innovation. In Chapter 4 Ashish Arora and Alfonso Gambardella explore the sources of innovation in the chemical industry, an industry that resembles some aspects of the energy sector in the chemical industry's focus on process development, and whose early development was significantly more global than those of the others discussed here. Chapter 5 presents Iain Cockburn, Scott Stern, and Jack Zausner's review of the roots of innovation in life sciences, an industry that has been the second largest recipient of federal research funding (after defense) and that is justly celebrated for the extraordinary productivity of the "innovation ecosystem" that links its public and private sectors.

Chapter 6 moves to David Mowery's review of the innovative history of the computer and semiconductor industries, and in Chapter 7 Shane Greenstein discusses the institutional roots of the innovations that led to the development of the Internet. Given the centrality of information technology and telecommunications to the modern economy it is particularly intriguing to be reminded of the critically important role that the federal government played in the development of both sectors - and to be exposed to careful discussions of the institutional structures and strategic decisions that made public support so very powerful in both industries. Finally, in Chapter 8 Josh Lerner concludes the book with a detailed focus on venture capital, one oftencited potential solution to the clean energy innovation problem. He notes that despite the fact that venture capital investments are a relatively small share of total R\&D investment they are exceedingly effective. However, he notes that while public policy public policy can help to maintain a healthy level of venture capital investment, direct government investment in venture capital funding can exacerbate the boom and bust cycles characteristic of the industry.

Taken together, these chapters do not provide a comprehensive review of innovation policy since several excellent reviews of innovation policy exist (See, for example, Branscomb and Keller, 1999; Cohen and Noll, 1991; Mowery and Nelson, 1999). Neither are they a comprehensive history of modern industrial innovation or of innovation policy. We were unable to persuade an expert on the history of innovation in the space or defense industries to participate in the project, for example, and with the notable exception of the chapters on agriculture and chemicals, the accounts by and large focus on the history of innovation in the United States. Mowery and his colleagues (2009) focus particularly on the history of innovation in the UK and on the relevance of the Manhattan and Apollo projects for our understanding of energy policy and their paper is highly recommended. We believe, however, that given the centrality of the industries we explore to modern economic growth and the critical role of U.S. public policy in supporting each of them our focus still yields important insights.

Lastly, we do not attempt to draw policy recommendations. This is in keeping with longstanding NBER policy - but it also reflects our awareness that the energy sector is importantly different 
from the industries discussed here. We hope instead to provide the kind of rich data that will allow the interested reader to draw their own conclusions.

The book's key themes

In broad outline, the chapters highlight three mechanisms that have historically served to support accelerated innovation: substantial, sustained and effectively managed federal funding for fundamental research, the generation of growing customer demand, either through procurement or through the market, and the enabling of aggressive competition, particularly from newly entering firms.

\section{Public Support for Fundamental Research}

The hypothesis that one of the central roles of public policy with respect to innovation is to fund "basic" or "fundamental" research is a well-established idea in the innovation policy literature (Bush, 1945), and rests on the observation that the gains from work designed to uncover core scientific principles and that is relatively remote from immediate commercial application are in general very difficult for private firms to appropriate. Much of the existing energy innovation policy literature stresses the central importance of this issue for U.S. innovation policy, stressing the relatively low levels of federal funding for fundamental energy research (Gallagher, Holdren and Sager, 2006; Nemet and Kammen, 2007; Newell, 2009; Ogden, Podesta \& Deutch, 2008).

Publicly funded energy research constitutes about 3 percent of the total federal R\&D budget (or less than 0.03 percent of gross domestic product). Annual energy R\&D funding decreased by more than half from a high of about $\$ 9$ billion (real 2009 dollars) in the late 1970s to about $\$ 3$ billion by the mid-1990s, where it remained for over a decade (Figure 1; Newell 2008). This represented a drop from about 25 percent to 7 percent of nondefense federal R\&D spending. Very recently this trend has reversed: the allocation to energy research increased by over 20 percent, surpassing \$4 billion in 2007, although this still represented less than 4 percent of total federal R\&D spending. Energy R\&D budgets increased modestly again in 2008, and in 2009 grew dramatically as a result of spending under the American Recovery and Reinvestment Act in response to the economic downturn. (Note that the Recovery Act spending includes significant amounts for technology demonstration projects.) While the Recovery Act spending represents a short-lived event, regular appropriations for energy R\&D are slated to increase to about $\$ 6$ billion by 2011 and the Obama Administration has sought to further increase funding for basic research. 
Figure 1. U.S. Federal Energy RD\&D Spending (1974-2009, with estimates for 2010-2011)

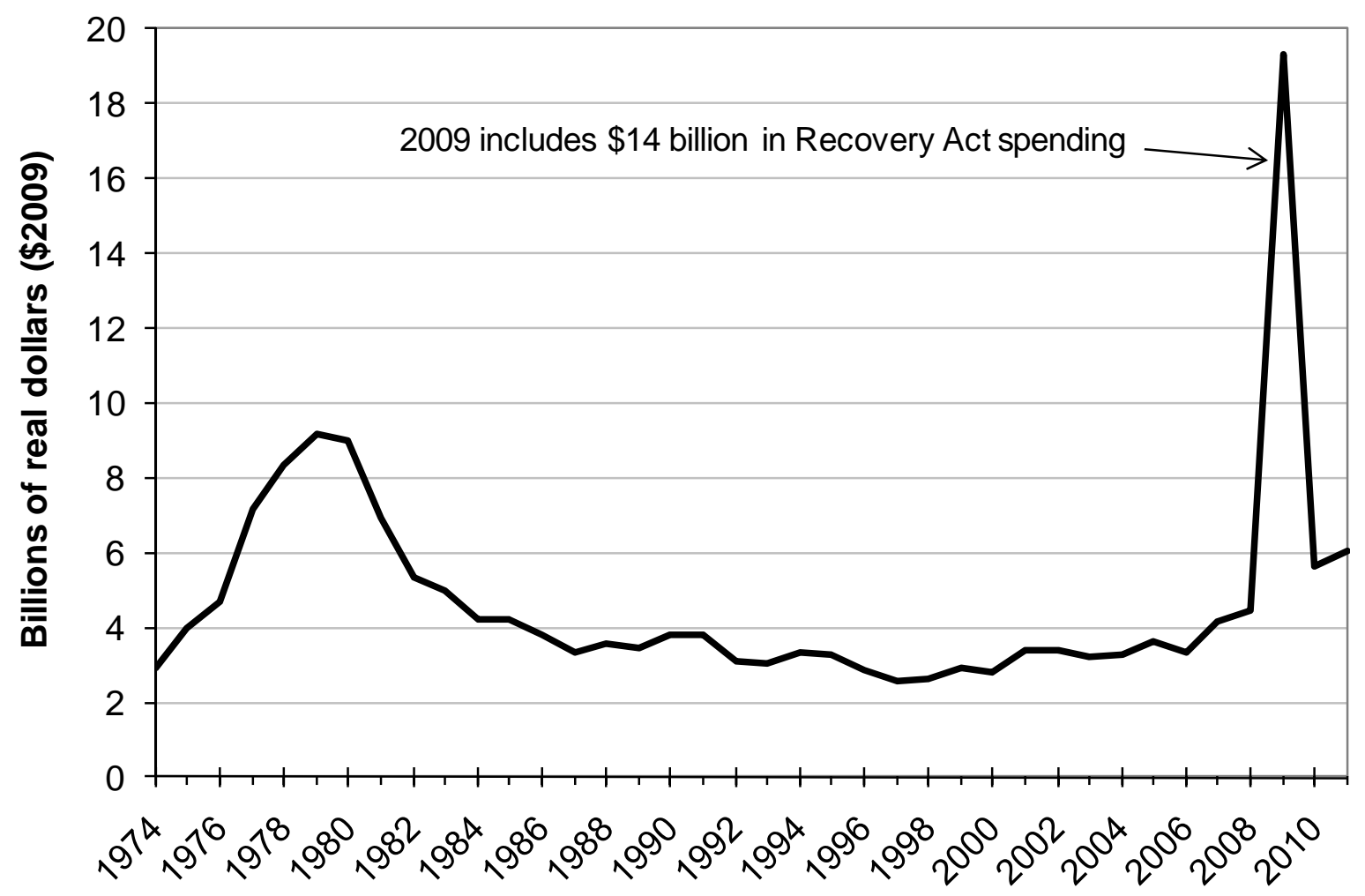

Source: IEA 2010. DOE 2010 for 2010-2011 estimates.

The most significant trend in recent years in federal R\&D spending has been the large rise in defense $R \& D$ and in health-related $R \& D$, which has increased from 25 percent of the federal nondefense R\&D budget in 1980 to 54 percent in 2007 (Figure 2). To place these figures in some perspective, in 2006 health expenditures accounted for 16 percent of GDP, energy expenditures accounted for 8-9 percent of GDP in recent years, and agriculture accounted for about 1 percent of GDP in 2004 (Newell 2008). 
Figure 2. U.S. Federal R\&D Spending by Budget Function (1955-2008)

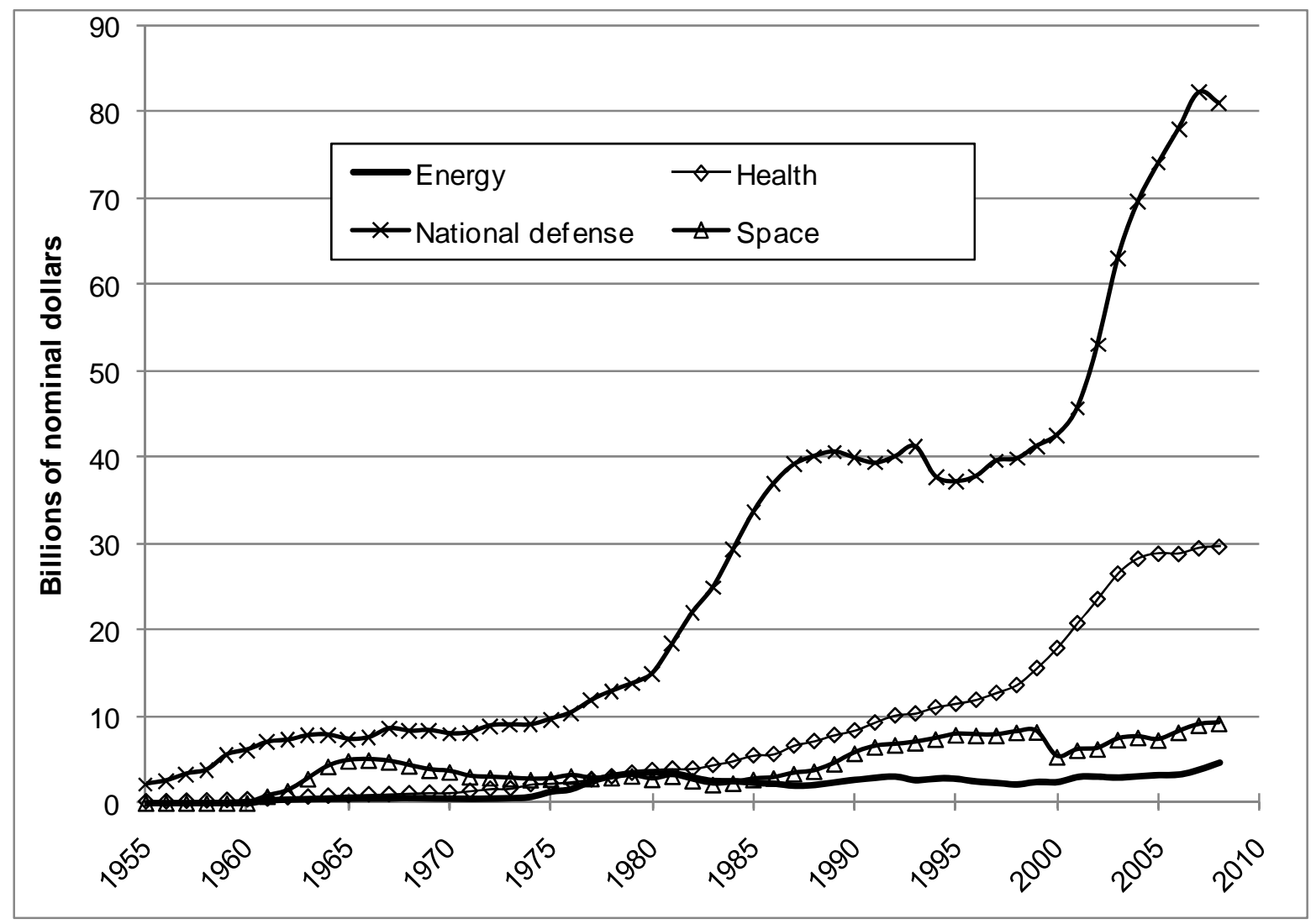

Source: NSF Science Indicators, 2009

Faced with these numbers, many analysts have suggested very significantly increasing federal commitment to fundamental energy research (Gallagher, Holden and Sager, 2006; Nemet and Kammen, 2007; Newell, 2009; Ogden, Podesta \& Deutch, 2008).

This idea is certainly consistent with the histories presented in our chapters. In every industry that we review, public support for fundamental research appears to have played a critical role in accelerating innovation in the industry, and there is some evidence that it has generated extraordinarily high returns. For example Wright and Shih (chapter x, below), suggest that marginal returns to public research in agriculture have been on the order of 45 to 60 percent. Similarly Cockburn, Stern, and Zausner (chapter x, below) highlight high, stable levels of public support as the primary foundation of industry's success in the life sciences, suggesting that this funding has led not only to many of the fundamental advances in scientific knowledge that have been indispensible to advances in modern molecular biology, but that it has also underwritten the development of a wide range of critical tools and techniques. For example, federal R\&D underwrote the gene-splicing technique pioneered by Stanley Cohen and Herbert Boyer in 1973 that opened up the modern field of genetic engineering. Federal support for R\&D was also critical to the early history of the semiconductor and computer industries. 
For example Mowery (chapter X, this volume), notes that although the first solid state transistor was developed privately by AT\&T, the firm's invention built on an extensive program of government funded wartime research, and that at the time it occurred AT\&T was in a competitive race with a publicly funded effort at Purdue University. Early work in the computer industry was entirely government funded, and from 1949-1959 federal funds were nearly 60\% of of computer-related R\&D spending. Even as private spending grew more important on a percentage basis, federal funding continued to increase, with federally funded basic research in computer science growing from \$65 million in 1976 to \$265 million in nominal dollars in 1995. The early development of the Internet rested entirely on federal funding of the seemingly obscure technology of large-scale packet switching - a technology that was part of a portfolio of research whose commercial applications were entirely unknown at the time. Even in the case of chemicals - an industry in which many critical scientific discoveries were made in private firms - much of the foundational science of the field was performed inside universities.

Each of our authors suggests, however, that it is not only the magnitude of the public commitment to research funding that is critical, but also the ways in which this funding is governed. In this respect the results we present here are very much consistent with those in the energy innovation policy community who have stressed that it is not enough for the federal government to dramatically increase funding for fundamental research: it is also critical that this research be managed appropriately (Lester 2009; Newell 2008; Ogden, Podesta, Deutch 2008).

Four themes in particular emerge from the chapters below. First, in every industry with the possible exception of chemicals, federal support for fundamental research was sustained over long periods of time. In both agriculture and life sciences, our authors explicitly point out that it took at least 20 years for fundamental research to have a notable effect on practice, and that it is the "stock" of knowledge, not the flow, that has the greatest impact on accelerating private sector innovation. For example, Wright and Shih note that it took several decades of development and learning before the U.S. land grant/State Agricultural Extension Service (SAES) system had acquired the scientific capacity and research base necessary to become an efficient system of innovation, and Cockburn, Scott and Zausner suggest that the recent "surge and retreat" in NIH funding over the last decade has probably resulted in a less productive innovation system and significantly distorted researcher incentives and career dynamics. In the case of IT, the ground breaking investments were made in the 1940s and 1950s, but IT did not have a significant effect on the productivity of the economy until the 1990s. These examples suggest that a sustained investment in energy innovation may have ground breaking implications - but that it may be years before these investments bear their full fruit.

Second, every author explores in some detail the ways in which effective governance steered a middle course between public funding of research that is so abstract and removed from potential application that it becomes isolated from practice, and the danger that public funds become so applied that they will substitute for private funds. This is an old concern in the technology policy literature (Cohen and Noll, 1991) and one that particularly concerns analysts of energy innovation policy (Newell, this volume). For example, Wright and Shih highlight the important role that locally supported, locally sited extension stations have played in ensuring that public funding for agriculture has been closely 
linked to actual practice. At the same time they cite a 1986 analysis of a public/private research effort in Canada's malting barley industry in which the authors estimate that social gains would have been 40 percent higher if the public researchers had focused only on more fundamental research. Arora and Gambardella, in their study of the chemical industry, highlight ways in which tight links between U.S. universities and the private sector have been instrumental in codifying and diffusing scientific advances made by the industry.

In the case of the life sciences, Cockburn, Stern, and Zausner note that federally funded research is administered overwhelmingly through investigator initiated, peer reviewed processes that are expected to ensure that the resources are allocated to genuinely promising scientific opportunities. Peer review processes are not without their drawbacks, but they have the great advantage of putting every proposal through a rigorous "quality control" process controlled by experts in the field and thus of increasing the odds that the research will contribute meaningfully to the body of fundamental science. The authors stress, however, that the tight links that typically exist between public and private researchers in this sector serve to mitigate the risk that publicly funded research will become too removed from the problems and issues that are likely to have real world application. Many publicly funded researchers work closely with private companies and many privately funded researchers publish widely in the public literature and participate in academic conferences.

In the case of the Internet, in contrast, Greenstein stresses the unique role of DARPA in enabling fundamental, leading edge research unencumbered by broader peer review. He focuses particular attention on DARPA's practice of funding "wild ducks" - creative researchers who were not constrained by institutional expectations. He also details the importance of involving a wide variety of researchers from many different backgrounds. Furthermore, program officers relied not only on their own deep knowledge of the technology in making critical funding decisions, but also on constantly bringing the network of researchers together to share ideas and to exchange criticism. They thus appear to have created a "market place for ideas" that was intensely robust and that generated very significant innovation. In both cases, the vast majority of publicly funded research was conducted through extramural performers, something that may also have contributed to the formation of effective links between research and practice. In general, the histories described in this volume highlight the fact that in each of these sectors, academic interaction with industry has been a two-way street - one in which important knowledge, expertise, people, and access to facilities have flowed in both directions.

Third, each of our authors stresses the important role that well designed institutional mechanisms have played in effectively diffusing the results of federally funded work. In semiconductors and computers, for example, the federal government ensured the effective transfer of knowledge by requiring grant recipients to conduct seminars and distribute publications that actively disseminated information to others in the field. When AT\&T developed the transistor, the military services that supported the company's transistor research also encouraged the dissemination of transistor technology. The proceedings of symposia funded by the military and held by Bell Labs (the research arm of AT\&T) in the 1950s were widely distributed, and one produced two thick volumes on semiconductor technology that became known as "the Bible." 
Greenstein's history of the Internet similarly provides a description of how DARPA's insistence that new technologies be embodied in prototypes and widely shared with other researchers led to the development of a powerful selection environment that mimicked the role of the market. Problems were quickly identified, and technologies that were found to be useful were immediately incorporated into other innovations, triggering a virtuous cycle of innovation that spread useful ideas rapidly around the research community.

Wright and Shih stress the critical role that the combination of SAESs and the federally funded agricultural extension service played in developing locally appropriate technologies and in ensuring their widespread diffusion. The authors explore the ways in which this structure balanced federal and state roles by combining federal financial support with state management of administration and direction of research. Wright and Shih suggest that the resulting structure provided an avenue to address local research needs while also exploiting interstate competition to motivate fruitful research.

The life sciences industry is also characterized by a particularly vibrant interchange between the public and private sectors. In their extensive discussion of the history and institutions that support this lively interface, Cockburn, Stern and Zausner stress that the life sciences innovation network is highly decentralized and involves multiple linkages between and among different institutions, including universities, start-up firms, established biotechnology companies, pharmaceutical firms, government, and venture capitalists. The authors identify a number of factors as particularly important to maintaining this network. For example, they credit the combination of the Bayh-Dole Act, which allowed federally funded researchers to take title to their inventions and the Diamond $v$ Chakrabarty decision, which established that genetically engineered organisms were eligible for patent protection, as instrumental in laying the foundations for the dynamic early-stage commercialization.

They also suggest that the creation of academic medical centers, which co-locate publicly funded researchers working on fundamental problems with doctors who are actively treating patients, was a particularly important institutional invention. Although this structure was initially regarded with some suspicion, it has proved to be very fruitful - the authors suggest that it has led to numerous Nobel prizes, and has to numerous findings that were both fundamental scientific discoveries and also the basis for new commercially oriented technologies.

Several chapters in this volume explore the efficacy of public/private partnerships as mechanisms to ensure that publicly funded research is widely diffused. Here no single lesson emerges. Arora and Gambardella, for example, explore the history of the synthetic rubber program in World War II. They suggest that the program met two of its initial objectives: it succeeded in greatly expanding the scale of synthetic rubber production and in improving synthetic rubber quality, and it attracted many new firms to the industry. It did not, however, make much progress towards its third goal, the generation and diffusion of significant new knowledge about polymers. Arora and Gambardella suggest that this may have been because the government insisted that participating firms adhere to a common recipe - thus slowing down the rate of innovation, and leading the many research programs within the participating firms to be kept rigorously distinct from the publicly funded efforts. 
In the case of agriculture, in contrast, Wright and Shih describe a number of cases in which public/private partnerships appear to have played an extremely positive role in both stimulating and diffusing critical knowledge. They note, for example, that research consortium models such as those adopted by the Latin American Maize Project (LAMP) and the Germplasm Enhancement of Maize Project (GEM) have been lauded for productively balancing public goods research with commercial viability. They also note, however, that while the U.S. Department of Agriculture has formed at least 700 cooperative research and development agreements with private firms, and while these have produced and commercialized some important innovations, researchers continue to be concerned that these arrangements will divert funds away from more basic research towards more applied work.

Last but not least, the research presented here shows that public funding of research can also play a critically important role in training the scientific and technical personnel who become the backbone of an innovative private sector.

Cockburn, Stern, and Zausner, for example, suggest that this dynamic has been fundamental to the development of the extraordinarily innovative private sector that characterizes the life sciences. They note, for example, that the practice of funding public research through peer reviewed extramural NIH funding has created a high level of competition for funds and has supported the development of departments in universities focused on the biosciences. Within these departments, grant-supported training of $\mathrm{PhD}$ and postdoctoral students engaging in frontier research has helped to create a mobile, knowledge-based workforce that has moved fluidly between industry and academia. Between the early 1970s and today, the number of life science doctorate holders employed in academia more than doubled and there has also been a significant expansion in the number of bachelors levels students who receive a degree in the life sciences fields. Universities have played a similarly critical role in the chemical industry by institutionalizing the learning being created by firms and by training students. Arora and Gambardella credit universities for creating the disciplines of petroleum engineering, chemical engineering, polymer chemistry, and polymer engineering.

Mowery makes the point that federal support of fundamental R\&D in semiconductors and computers played an instrumental role in building the "R\&D infrastructure" - the institutions that identified and trained the highly skilled people whose work was fundamental to innovation in the commercial sector. For example in the case of the software industry, the SAGE air defense project acted as a "university" of sorts for hundreds of software programmers - a development that laid the foundation for the future development of the industry within the United States. Similarly, the (much later) development of the so called "shrink wrapped" or "mass market" software industry was greatly aided by a (largely federally funded) university-based research complex. Greenstein makes an analogous point in the case of the Internet, suggesting that many of the key players who went on to private sector careers developed their expertise in the context of early government-funded work.

Taken together the work presented here is thus broadly consistent with much of the current energy innovation policy literature: in the highly innovative industries reviewed here public 
funding for fundamental research was not only significant and sustained but also managed in such a way that it was tightly linked to practice, widely diffused and led to the generation of a highly trained private sector workforce. The ways in which this was accomplished, however, differ significantly across each industry, with each history highlighting governance mechanisms that may be worth considering in the energy context.

\section{Demand and Induced Innovation}

Rapidly growing demand plays two key roles in stimulating innovation. First and foremost, it signals a plausibly large and potentially rapidly growing market - something that greatly accelerates private-sector investment in innovation and the rapid diffusion of new technologies. Second, and perhaps more subtly, growing demand provides an important opportunity for immediate feedback from the market, whereby new product development underpins innovation that is more directly responsive to real market needs and less likely to fall prey to the isolation of the ivory tower.

In every one of the sectors explored here, rapidly growing demand triggered both extensive private sector investment and extensive diffusion of new technology. For example in Cockburn, Stern, and Zausner's review of innovation in the life sciences suggests that one of the reasons R\&D investment rates in the biopharmaceutical industry have remained so consistently high is because private firms have been consistently assured of robust demand for innovative products, as historically so many health care needs have remained unmet. The authors note that the nature of demand for biopharmaceuticals has profoundly affected the life sciences innovation system. Intrinsically high willingness to pay for products that extend life or improve the quality of lifeespecially in the notably price-insensitive U.S. healthcare delivery system - has translated into relatively price-inelastic and stable demand. As a result, firms have been able to secure significant returns over a long period of time by focusing on the development and commercialization of innovative and novel biotherapeutic compounds. In agriculture, Wright and Shih find that similarly unmet needs - for higher yields and improved crop varieties able to withstand extreme weather, weed encroachment, and constantly evolving pests - have acted as a strong stimulus to innovation.

In both the semiconductor and computer industries, the large-scale entry of private firms coincided with a decline in prices, partly as a result of early government purchases, and an explosion in demand as both technologies allowed customers to do things that had never been done before. Similarly, the early commercialization of the Internet - and the excitement about its potential uses - was associated with a rush of private firms into the industry and a dramatic increase in the pace of innovation. Arora and Gambardella, in their chapter on the chemical industry, suggest that the explosion in demand for chemicals that accompanied the rapid industrialization of the early twentieth century was a critical factor in persuading private firms to invest heavily in chemical research. They also note that a lack of commercial demand was almost certainly the most important factor leading to the perceived failure of the government's Synfuels programs. 
As many scholars have noted, one of the major barriers to the replication of these kinds of dynamics in the energy industry is the fact that "low carbon" or "carbon free" energy is typically indistinguishable from "dirty" energy at the point of consumption. In the industries whose history we include here - in agriculture, chemicals, semiconductors, computers, the Internet and biopharmaceuticals - once the technology reached some critical threshold of performance, demand exploded because the new technologies offered dramatic improvements over existing products, in many cases meeting consumer needs that had never been met before. This is unlikely to be the case with energy innovation.

Many authors working within the energy innovation policy literature have therefore argued that the single most important thing public policy can do to support the accelerated development and deployment of clean energy technologies is to create demand for low-carbon energy (Aghion et al, 2007; Anadon et al. 2009a, 2009b; Newell 2008, 2010; Stavins, 2008; Weiss and Bonvillian 2009). Attention has focused on two kinds of mechanisms: on the creation of a "price" for carbon through some kind of tax or cap and trade regime; and/or on the direct creation of markets through, for example, the imposition of renewable energy standards in energy purchasing or through the direct government support of "first in class" technology implementation through subsidy or purchase.

Proponents of the first approach stress its likely economic and technical efficiency (Stavins, 2008; Newell 2010; Aghion et al 2007). For example Mowery et al. (2009) suggest that a "Manhattan" or "Apollo" project approach is not an appropriate model for clean energy innovation. In the defense and space industries, the government can entirely define the nature of customer demand, because it is the final customer. In the case of clean energy, however, Mowery et al. argue that it is deeply implausible to think that any discrete government program could foresee the precise technological solutions that will be appropriate. This is particularly true given that these technologies will need to be deployed throughout the world by many different actors, the deployment decisions will require huge outlays of private funds, and their largely embryonic state means that they will continue to evolve and improve over many years.

Proponents of the second approach, in contrast, stress the need for public subsidies to cross the "valley of death" between technological proof of concept and first commercialization, suggesting that this valley is likely to be particularly wide and expensive in the case of energy (Lester 2009; Ogden, Podesta and Deutch, 2008).

The results presented below are consistent with both perspectives. On the one hand, there are several cases in which the federal government acted as the "first customer" for a new technology, arguably providing the critical support that was required to bridge the gap between prototype and private commercialization. Mowery's account of the early development of the semiconductor industry is an intriguing example of this dynamic in action. He documents how the prospect of large military procurement contracts in the early years of the semiconductor industry acted as a "prize," stimulating widespread entry and extensive innovation. He also details the important role that early military demand played in driving up industry production volumes and driving down production costs to the point where the new technology became commercially viable. He contrasts the success of these early efforts with the much more mixed track record of the Very High Speed Integrated Circuit (VHSIC) program - an early 1980s program that failed to meet its 
objectives and failed to successfully compete with the U.S. semiconductor market, which by then was dominated by commercial applications.

Mowery also documents the central role that federal procurement played in the early days of the computer industry. The first electronic U.S. digital computer was purchased by the military, and the first fully operational stored program computer built in the United States was purchased by the National Bureau of Standards. Even in the case of IBM's 650 -- the most commercially successful machine built in the 1950s -- the projected sales of 50 machines to the federal government was critical to IBM's decision to move the computer to full scale commercial development. In the 1970s and 1980s, the government's role as purchaser of high performance computer equipment remained significant. Mowery further argues that federal procurement fostered the early development of the software industry. The rapid growth of the industry between 1969 and 1980 that gave the U.S. industry a worldwide advantage was spurred by federal willingness to invest in large, complex software development projects at a time when the commercial market for such projects did not exist.

Early government demand also looms large in Greenstein's account of how the Defense Advanced Research Projects Agency (DARPA) funded research that proved ultimately to be immensely useful despite the absence of immediate commercial demand. Greenstein makes the point that DARPA's investments in the development of large-scale packet switching and a "networks of networks" were considered highly risky, and that no one foresaw any commercial application for them. This is not to say, however, that the early research went forward without any interaction with potential customers, or without some sense of what demand might look like. Rather, the military had identified potential military uses for some of the new technology, and this potential military application shaped the early DARPA research.

Similarly while it is the case that in none of the industries whose history is outlined below did the government explicitly set a price for the new technology, Cockburn, Stern, and Zausner suggest that in the case of the life sciences the government has played a critical role in sustaining demand for innovative biopharmaceuticals. They hypothesize that--“whether by accident or design"-- the interaction between the patent system, the FDA regulatory process, and the way care is paid for within the U.S. healthcare system, provide strong incentives for breakthrough innovation. The combination of a high willingness to pay for products, insurance that insulates purchasers from paying the marginal price, and the Hatch-Waxman regulatory framework provide strong incentives for the private sector to develop blockbuster therapies. These factors also provide incentives to develop a stream of innovations over time, as the threat of generic entry upon patent expiration means that the returns to any single innovation are transitory).

What are the implications of these histories for our understanding of the role of government in creating demand for low-carbon energy? The industries we explore here differ crucially from energy in that one of the most important outcomes of innovation in each of them has been the creation of highly differentiated products that have met hitherto unmet needs, while "clean" energy cannot be easily differentiated at the point of delivery. It is thus difficult to imagine creating demand for low-carbon energy without government intervention - in the form of a price for greenhouse gas emissions, purchase mandates or subsidies. Much ink has been spilled on the 
question of which of these interventions is likely to be the most economically efficient (See, for example, Popp et al., 2008 and Jaffe et al 2005). The histories contained in this volume do not attempt to resolve this debate, but they do suggest that each may be effective, and they underscore the imperative of inducing clean energy demand if we are to see substantial, sustained, private-sector investment in energy innovation and the rapid deployment of new technologies.

\section{Enabling Competition: Antitrust, Intellectual Property and Standards Policy.}

Accelerating innovation requires increasing both the supply of and the demand for new technologies. Beyond supply and demand, however, the theme that emerges most clearly from our histories is the important role that public policy has played in fostering vigorous competition and "markets for technology" in each industry and the centrally important role that this competition has played in accelerating innovation. Here again our histories suggest that there is no single policy or set of policies that is always appropriate, but that policy design must be actively tailored to the structure of the industry and the particular circumstances of the market. They focus attention on three policy instruments in particular: antitrust, intellectual property and support for public open standards.

In the case of chemicals, Arora and Gambardella explore in some depth the role that appropriately narrowly-defined patents and aggressive antitrust enforcement have played in encouraging entry in general and the rise of specialized engineering firms in particular. They note that new technologies in the industry have typically diffused extraordinarily fast, largely because of the presence of a robust market for technology fueled by the activities of small, independent specialized engineering firms. These firms not only build about 75 percent of all new plants, allowing easier entry into the industry, but are also responsible for about 35 percent of all new process inventions. Arora and Gambardella suggest that the existence of this market reflects the fact that patents in chemicals are both precise and narrowly specified. This makes the patents effective in protecting particular innovations, but also allows competitors to enter the industry in closely related areas.

Arora and Gambardella also suggest that antitrust action has accelerated the widespread industry practice of licensing, focusing particularly on the cases of Standard Oil and DuPont. In 19091910, Standard Oil scientist William Burton developed the first commercially successful cracking process. It was a major innovation in refining technology, but Standard Oil was reluctant to invest in the process. However as a result of an anti-trust suit, the original Standard Oil was broken up into several firms in 1911, among which was Standard Oil of Indiana, where Burton worked. Standard Oil of Indiana not only commercialized Burton's process, but also licensed it to a number of other oil refiners. Similarly, Du Pont was split into three separate firms following a successful anti-trust suit in 1913 that also helped to convince Du Pont's managers that the only path to future growth lay in entering new markets through innovation, rather than through the acquisition of existing producers. 
In the life sciences, Cockburn, Stern and Zausner note that there are multiple routes to the highly diversified, highly innovative private sector "ecosystem" that characterizes the industry. The fact that this is one of the very few industries in which patent rights can be crisply defined appears to play an important role - notably by undergirding a vigorous biotechnology sector whose numerous small firms are largely venture capital funded. They note that the industry has seen the founding of more than 1,300 biotechnology companies in the United States and approximately 5,000 worldwide, and that by the early 2000 s, $25-40$ percent of all pharmaceutical sales came from products having their origins in biotechnology. There has also been significant entry of specialized suppliers of biomedical materials and tools (e.g., gene sequencers and biomaterials); the development of contract research organizations that can provide expertise in areas such as early-stage clinical trials; and the development of specialized managers, lawyers, and venture capitalists, who together can facilitate more effective transactions in what has become an increasingly complex web of relationships between academe, entrepreneurs, and downstream firms. Their analysis parallels Arora and Gambardella's suggestion that the emergence of a well functioning "market for technology" can be hugely valuable in both stimulating private sector innovation and in supporting its widespread diffusion. They stress the fact that both the structure of demand and the nature of regulation has meant that competition in the industry has been largely focused around innovation.

Greenstein's chapter describing the history of the Internet is one of the most eloquent on this set of issues. He suggests that effective competition was critical to the development of the Internet, and rested on three key factors: "economic experiments, vigorous standards competition, and entrepreneurial invention." He stresses the crucial role that federal policy played in supporting all three factors. On the one hand many of the established firms in the industry - including AT\&T, the "Baby Bells" and IBM - actively rejected the possibility of investment in commercializing services related to TCP/IP (the technological "core" of what later became the internet) in the late 1980s. On the other, long standing regulation of the telecommunications industry that favored new entry meant that the commercialization of the Internet was accompanied by a dramatic wave of new firm foundation.

Greenstein's account also explores the ways in which the process of standard setting in the industry was instrumental in supporting widespread, highly distributed innovation. Many of the key patents in the industry were publicly owned. This public ownership, coupled with the fact that early control of the technology rested largely in the hands of public sector researchers, built a set of processes for standard setting that has been transparent and highly participatory. Greenstein makes the point that while this process has sometimes been frustrating, it has enabled the development of a highly complex value chain in which private, proprietary "platforms" coexist with public technologies in a way that makes it possible for small, innovative firms to innovate successfully without having to reinvent the entire system.

Mowery notes the importance to the semiconductor industry of both AT\&T's ongoing antitrust litigation and of the government's procurement policies. Both encouraged the widespread diffusion of semiconductor technology and subsequent rapid entry into the industry. In the early 1950s AT\&T was reluctant, for antitrust reasons, to expand beyond its core base of telecommunications, thus leaving sales of the new technology into other applications as a 
tempting market for new entrants. At the same time federal policies - driven partly by the desire to have "second sources" available for key military components - encouraged widespread diffusion of the new knowledge. For example Mowery describes a symposium held at Bell labs in 1951 attended by 130 industrial representatives, 121 military personnel and 41 university scientists whose proceedings were widely distributed at government expense. The military was also willing to award large procurement contracts to newly founded firms, another mechanism that Mowery suggests was instrumental to the development of a highly competitive, highly innovative market structure that he contrasts with the very different semiconductor industries that emerged in Germany and Japan.

Mowery describes a similar dynamic in the case of computers-documenting how the military's belief that a strong technical infrastructure in support of innovation could only be built by the widest possible dissemination of technology — which led them to both use federal procurement policies to support new firms and to invest aggressively in information diffusion. He also describes how the IBM antitrust suit and subsequent consent decree was almost certainly instrumental in encouraging widespread entry into the hardware industry and the entry of many independent software vendors. He further observes that many of these entrants had been suppliers of computer services to federal government agencies. He speculates that U.S. import policies - which were notably more liberal than those adopted by Western European and Japanese governments - also played an important role in stimulating the competitiveness of the IT industry and the rapid declines in price/performance ratios that so accelerated the adoption of IT and the subsequent U.S. dominance of the industry.

In agriculture, in contrast, Wright and Shih voice deep concern over the role that patents play in the industry. They note the increasing evidence that multiple, mutually blocking intellectual property claims on inputs are hindering access to research tools that can be incorporated in the marketed products of agricultural research (Wright and Pardey 2006; Pardey et al. 2007). The authors suggest that the increasing concentration of the industry -for example, one estimate suggests that the top ten firms own more than half of all the agricultural biotech patents granted through 2000 - is plausibly an attempt to retain "freedom to operate" by the major players and suggest that it may retard innovation in the industry. Even more critically, they suggest that the rising application of intellectual property rights to plant components and processes imposes high transaction costs for researchers who must acquire or license fragmented proprietary inputs to develop and commercialize a single downstream innovation. They further suggest that patents on locked-in but otherwise non-crucial genetic technologies have been retarding innovation and affecting the market structure of private research.

Although some energy policy analysts have explored the role of intellectual property regimes in shaping energy innovation (Reichman et al. 2008; Popp et al 2008; Sagar and Anadon, 2009), this has not been an area of central concern to scholars working in the field. Perhaps this approach reflects the belief that the scale of energy investment is such that only large established firms can be expected to introduce major innovations - but the importance of new entry to recent progress in both wind and solar technologies at least raises the question of whether some of the instruments that appear to have been important in the industries we study might also play an important role in stimulating vigorous, innovation focused competition in the energy industry. 


\section{$\underline{\text { Conclusions }}$}

At the broadest level the histories presented here are very much consistent with widely held views within the energy innovation policy literature. In general, this literature has suggested that greatly increasing rates of energy innovation requires creating significant demand for low carbon technologies, substantially increased federal funding for "well-managed" research, and in at least some cases support for the initial deployment of new technologies. As the other markets explored in this volume do not face the same degree of unpriced environmental externality, there is no straightforward equivalent to a carbon price in the history of agriculture, chemicals, IT or biopharmaceuticals. Nonetheless, our authors outline a number of ways in which public policy has often stimulated demand, particularly in the early stages of a technology's evolution, and confirm that the expectation of rapidly growing demand appears to have been a major stimulus to private sector investment in innovation. Each history also confirms the centrality of publicly funded research to the generation of innovation, particularly in the early stages of an industry's history, and highlights a range of institutional mechanisms that have enabled it to be simultaneously path breaking and directly connected to industrial practice.

Our histories depart somewhat from the bulk of the energy innovation policy literature in focusing attention on the role of vigorous competition - particularly entry - in stimulating innovation, suggesting that in several industries a mix of public policies - including procurement, antitrust and intellectual property protection - played an important role in stimulating innovation by encouraging extensive competition and entry by newly founded firms. Many of the most innovative industries profiled here have been characterized by a lively "innovation ecosystem" that both rapidly incorporates the results of publicly funded research and supports widespread private sector experimentation and rapid entry. There are, of course important differences between the industries profiled here and the energy sector, but we believe that exploring the potential of these kinds of innovation ecosystems in clean energy might be a fruitful avenue for future research. 


\section{$\underline{\text { References }}$}

Acemoglu, D., P. Aghion, L Burszytyn and D. Hemous "The Environment and Directed Technological Change" Mimeo, Harvard University, April 2010. Available on line at: http://www.economics.harvard.edu/faculty/aghion/files/Environment\%20and\%20Directed.pdf

Aghion P, Blundell R, Griffith R, Howitt P and Prantl S (2007) "Entry, Innovation, and Growth: Theory and Evidence", Review of Economics and Statistics.

Aghion, P, N. Bloom and R. Blundell, Competition and Innovation: An Inverted-U Relationship. Quarterly Journal of Economics, Vol. 120, No 2, Pages 701-728. May 2005.

Anadon, Laura Diaz and John P. Holdren. "Policy for Energy Technology Innovation." Chap. 5 in Acting in Time on Energy Policy. Washington, D.C.: Brookings Institution Press, May 2009.

Andadon, Laura Diaz, Kelly Sims Gallagher and Mathew Bunn: "DOE FY 2010 Budget Request and Recovery Act Funding for Energy Research, Development, Demonstration, and Deployment: Analysis and Recommendations" Working paper, Energy Technology Innovation Policy Group, the Belfer Center, the Kennedy School of Government at Harvard University. June 2009.

Baldwin, Carliss and Kim Clark: Design Rules, Vol. 1: The Power of Modularity. MIT Press 2000

Berndt, Ernst R. and Neal J. Rappaport, "Price and Quality of Desktop and Mobile Personal Computers: A Quarter Century Historical Overview," American Economic Review, Vol. 91, No. 2, May 2001, 268-273.

Branscombe, L.M. and J.H. Keller Investing in Innovation: Creating a research and innovation policy that works. 1999. The MIT Press, Cambridge Massachusetts.

Brynjolfsson, Erik and Lorin M. Hitt, Computing Productivity: Firm-Level Evidence. Review of Economics and Statistics, November 2003, Vol. 85, No. 4, Pages 793-808

Bush, Vannevar "Science, the Endless Frontier". Report to the President, 1945

Clarke, Leon. E., M. Wise, M. Placet, C. Izaurralde, J. Lurz, S. Kim, et al. 2006. Climate Change Mitigation: An Analysis of Advanced Technology Scenarios. Pacific Northwest National Laboratory, Richland, WA.

Cockburn, I. "Is the Pharmaceutical Industry in a Productivity Crisis?" Chapter in A. Jaffe, J. Lerner, and S. Stern (eds.) Innovation Policy and the Economy, Volume 7. MIT Press for the National Bureau of Economic Research, Cambridge MA. 2007.

Cohen, Linda and Roger Noll: The Technology Pork Barrel, Brookings, 1991 
U.S. Department of Energy (DOE). 2010. FY2011 Congressional Budget Request: Budget Highlights. Washington, DC: U.S. DOE.

Duggan ,MG and William N. Evans (2008) "Estimating the Impact of Medical Innovation: A Case Study of HIV Antiretroviral Treatments," Forum for Health Economics \& Policy: Vol. 11: Issue 2 (Economics of the HIV Epidemic), Article 1. Available at: http://www.bepress.com/fhep/11/2/1

Edmonds, Jae, M. A. Wise, James J. Dooley, S. H. Kim, S. J. Smith, Paul. J. Runci, et al. 2007. Global Energy Technology Strategy: Addressing Climate Change. Joint Global Change Research Institute, Battelle Pacific Northwest National Laboratory, College Park, MD. Energy Information Association Annual Energy Outlook, 2008

Energy Information Administration (EIA). 2010. International Energy Outlook 2010. DOE/EIA0484(2010). Washington, DC: EIA.

Gallagher, K.S, J.P. Holdren and A.D. Sagar. "Energy Technology Innovation” Annual review of Environmental Resources. 2006. 31: 193-237

Gompers, Paul, and Josh Lerner, 1999, Capital Market Imperfections in Venture Markets: A Report to the Advanced Technology Program, Washington, Advanced Technology Program, U.S. Department of Commerce.

Grübler, Arnulf and Nebojša Nakićenović and David Victor. "Modeling Technological Change: Implications for the Global Environment. Annu. Rev. Energy Environment. 1999 24: 545-69.

International Energy Agency (IEA). 2009. World Energy Outlook 2009. Paris: OECD/IEA.

- 2010. Energy Technology RD\&D Budgets (2010 Edition). Paris: OECD/IEA.

Henderson, Rebecca. "Of Life Cycles Real and Imaginary: The Unexpectedly Long Old Age of Optical Lithography" Research Policy, 1995, Vol. 24, pp 631-643.

Jorgenson, D.W. "Productivity and Growth: Alternative Scenarios," in D.W. Jorgenson and C.W. Wessner, eds., Productivity and Cycliality in Semiconductors (National Academies Press, 2004]

Jorgenson, D. W. and K. Stiroh (2000). "Raising the Speed Limit: U.S. Economic Growth in the Information Age," Brookings Papers on Economic Activity 1: 125-211.

Lester, Richard. “American's Energy Innovation Problem”. MIT-IPC-Energy Innovation Working Paper 09-007, November 2009. Available on line at: http://web.mit.edu/ipc/research/energy/pdf/EIP_09-007.pdf 
Lichtenberg, Frank "The impact of new drug launches on longevity: evidence from longitudinal disease-level data from 52 countries, 1982-2001," International Journal of Health Care Finance and Economics 5, 2005, pp. 47-73.

Manne and Richels. 1992. Buying Greenhouse Insurance. Cambridge: MIT Press.

Mowery, D.C., and R.R. Nelson, “Conclusion: Explaining Industrial Leadership,” in D.C. Mowery and R.R. Nelson, eds., Sources of Industrial Leadership (New York: Cambridge University Press, 1999)

Mowery, David and Nathan Rosenberg "The influence of market demand upon innovation: a critical review of some recent empirical studies." Research Policy, 8 (1979) 102-153

Mowery, David C., Richard R. Nelson and Ben R. Martin "Technology Policy and Global Warming: Why New Policy Models are Needed (Or Why Putting New Wine in Old Bottles Won't Work). Working paper, Nesta, Summer 2009. Available on line at: http://www.nesta.org.uk/library/documents/technology-policy-global-warming.pdf

Narayanamurti, Venakatesh, Laura Anadon, and Ambuj Sagar. 2009a. "Institutions for Energy Innovation: A Transformational Challenge." Energy Technology Innovation Policy research group, Belfer Center for Science and International Affairs, Harvard Kennedy School, September. Available at:

http://belfercenter.ksg.harvard.edu/publication/19572/institutions_for_energy_innovation.html

Narayanamurti, Venkatesh, Laura D. Anadon, and Ambuj D. Sagar. 2009b. "Transforming Energy Innovation." Issues in Science and Technology (Fall 2009): 57-64.

National Science Foundation, Division of Science Resource Statistics, 2008

Nelson, Richard National Innovation Systems: A comparative analysis Oxford University Press, 1993.

Nemet, G.F. and D.M. Kammen: "U.S. energy research and development: Declining investment, increasing need, and the feasibility of expansion.” Energy Policy, 35 (2007) 746-755.

Newell, Richard G. 2010. The role of markets and policies in delivering innovation for climate change mitigation. Oxford Review of Economic Policy 26(2): 253-269.

Newell, Richard “A U.S. Innovation strategy for Climate Change Mitigation. The Brookings Institution, Discussion Paper 2008-15, December 2008. Available at: http://www.brookings.edu/papers/2008/12 climate change newell.aspx.

P. Ogden, J. Podesta and J. Deutch. "A new strategy to spur energy innovation”. Issues in Science and Technology, Winter 2008. 
Pardey PG, J James, J Alston, S Wood, B Koo, E Binenbaum, T Hurley, and P Glewwe. (2007) Science, Technology, and Skills [International Science and Technology Practice and Policy (INSTEPP). Rome: CGIAR and Department of Applied Economics, University of Minnesota, for FAO.

Popp, David, Richard G. Newell, and Adam B. Jaffe. 2008. Energy, the environment, and technological change. Prepared for publication in Handbook of Economics of Technical Change, ed. Bronwyn H. Hall and Nathan Rosenberg. Oxford: North-Holland.

Reichman, Jerome, Arti K. Rai, Richard G. Newell, and Jonathan B. Weiner. 2008. "Intellectual property and Alternatives: Strategies for a Green Revolution.” Energy, Environment, and Development Programme Paper 08/03. Chatham House, London, UK.

Sagar, A.D. and L.D. Anadon "Climate Change: IPR and Technology Transfer" Working paper prepared for the UNFCCC Secretariat, September 2009.

Schumpeter, Joseph A. (1934) The Theory of Economic Development, Cambridge, MA: Harvard University Press, 1934.

Stavins, Robert. "Addressing Climate Change with a Comprehensive U.S. Cap and Trade System" The Oxford Review of Economic Policy, Volume 24, Number 2, 2008, pp. 298-321.

Weiss, Charles and Bonvillian, William: Structuring an Energy Technology Revolution. The MIT Press, 2009.

Wright BD, and PG Pardey. (2007) "Changing intellectual property regimes: implications for developing country agriculture." International Journal of Technology and Globalization, 2(1/2):93-114. 